\title{
Introducing life cycle thinking in product development - A case from Siemens Wind
} Power

Bonou, Alexandra; Olsen, Stig Irving; Hauschild, Michael Zwicky

\section{Published in:}

CIRP Annals : Manufacturing Technology

Link to article, DOI:

10.1016/j.cirp.2015.04.053

Publication date:

2015

Document Version

Peer reviewed version

Link back to DTU Orbit

Citation (APA):

Bonou, A., Olsen, S. I., \& Hauschild, M. Z. (2015). Introducing life cycle thinking in product development - A case from Siemens Wind Power. CIRP Annals : Manufacturing Technology, 64(1), 45-48.

https://doi.org/10.1016/j.cirp.2015.04.053

\section{General rights}

Copyright and moral rights for the publications made accessible in the public portal are retained by the authors and/or other copyright owners and it is a condition of accessing publications that users recognise and abide by the legal requirements associated with these rights.

- Users may download and print one copy of any publication from the public portal for the purpose of private study or research.

- You may not further distribute the material or use it for any profit-making activity or commercial gain

- You may freely distribute the URL identifying the publication in the public portal 


\title{
Introducing life cycle thinking in product development - a case from Siemens Wind Power
}

\author{
Alexandra Bonou*, Stig I. Olsen, Michael Z. Hauschild (1) \\ Quantitative Sustainability Assessment, Department of Management Engineering, Technical University of \\ Denmark, Lyngby, Denmark
}

* To whom correspondence should be addressed; e-mail: abon@dtu.dk, Tel.: (+45) 53234656

\begin{abstract}
How can use of LCA improve the environmental sustainability of wind industry products? An analysis of a case study from Siemens Wind Power identifies the knowledge offered by LCA that is relevant to each step of the product development process (PDP). The study illustrates the difference that this knowledge can make to the decision making in the PDP and to the environmental sustainability of the product. Based on these findings, the study concludes with a discussion of barriers for LCA integration in the PDP of complex products and possible measures to overcome them.
\end{abstract}

\section{Keywords}

Product development, Lifecycle, Wind Energy

\section{Life Cycle thinking in Wind Power technology development}

The total installed capacity of wind power has experienced a $25 \%$ annual increase rate over the last decade and International Renewable Energy Agency's (IRENA) projections predict a 500\% increase in the electricity generation from wind energy between 2010 and 2030 [1].This creates a challenge for the manufacturers to keep satisfying the growing demand and market requirements and calls for ensuring the sustainability of production and product development.

During the last decade major manufacturers as well as system operators and academia have published extended life cycle assessments (LCA) of their products and systems [e.g 2,3]. Despite the transparency of the reporting and its marketing value, little has been published on the integration of life cycle thinking in daily routines in the product development process (PDP) or in the strategic planning of the manufacturers.

Learnings from mature industries such as the automotive highlight the value of integrating such considerations in their PDP in order to set the focus right on ecodesign to avoid trade-offs between environmental impacts and to set road maps for target setting and innovation [4,5]. The business benefits of integrating life cycle considerations and transitioning from a single product to a product service system perspective have also been discussed [6-8]. As for the operational part there is an increasing number of publications linking LCA to product development and management processes and coupling environmental assessments with intelligence systems for effective product life cycle management and decision support towards sustainability [9-13]. However, to invest and effectively uptake tools and services that support LCA integration to daily operations, the business case needs to be proved to the decision makers. In this sense the challenge related to first introducing life cycle 
thinking in an organisation and arguing for the value brought to various stakeholders across the system still remains relevant.

The fact that the wind power industry is young and processes still immature and open to changes makes it fertile for idea exploration in terms of life cycle thinking integration. In the context of responsible innovation it is hence the intention of this paper to use the case of a wind turbine rotor blade manufactured by Siemens Wind Power, one of the global market leaders in the sector, and prove the value brought by integrating LCA in the existing PDP which is currently under development. In the process, conditions, process requirements and barriers that need to be overcome will be identified.

\section{Rotor blade Product Development Process (PDP)}

To evaluate where in the PDP the knowledge brought by LCA can make a difference, a mapping of the current PDP is done (Table 1). On the strategic level, which is prior to the PDP and outside the scope of the current paper, the need is identified in the market for a new solution (e.g. more power capacity). Then a corresponding product that could provide this solution (e.g. an upgraded blade with larger swept area) is developed following a stage gate PDP model [14] which has a linear form and is divided into five technically distinguished steps (Table 1): There is an initial scoping and feasibility exploration of technical solutions which are prioritized before the best enter R\&D. There the product design is specified, tested and validated. At the end of the R\&D when all the knowledge is gathered and the product and production details have been settled the PDP ends and the project is handed over for commercialization. Within this PDP six clusters of internal stakeholders have been identified as giving technical input: supply chain, factories, design, sales, field projects and service.

Each cluster is mobilized in the assessment of alternative technology ideas to collect technical cost and risk data and evaluate them against criteria related to technical specifications and cost estimations ensuring product quality and economic feasibility and competitiveness within guaranteed health and safety conditions. The gathered relevant knowledge is shared via adequate deliverables that are reviewed and evaluated by the management team at the end of each step 'gate'. The approval of the deliverables means continuation of the business case, locking of the relevant decisions and passing to the next gate

Table 1. PDP steps, corresponding requirements locked at the end of each step and potential application of LCA

\begin{tabular}{|c|c|c|c|c|c|c|c|c|}
\hline \multirow[b]{2}{*}{ Met requirements } & \multicolumn{2}{|c|}{ Product definition } & \multicolumn{3}{|c|}{ Design } & \multirow[b]{2}{*}{ 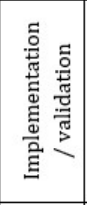 } & \multirow[b]{2}{*}{ 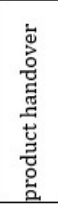 } & \multirow[b]{2}{*}{ 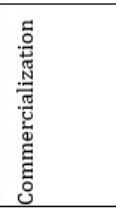 } \\
\hline & 离 & 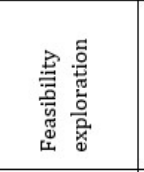 & 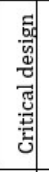 & 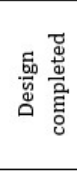 & 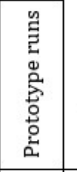 & & & \\
\hline Product requirement specification (PRS) & $\mathrm{x}$ & & & & & & & \\
\hline Product design specification (PDS) & & $\mathrm{x}$ & & & & & & \\
\hline $\begin{array}{l}\text { Design drawings, manufacturing concepts, serviceability and testability } \\
\text { specifications, critical suppliers qualification }\end{array}$ & & & $\mathrm{x}$ & & & & & \\
\hline Part specifications, tools processes and manufacturing technologies & & & & $\mathrm{x}$ & $\mathrm{x}$ & $\mathrm{x}$ & & \\
\hline Specification of purchased materials, parts, tools and technologies & & & $\mathrm{x}$ & $\mathrm{x}$ & $\mathrm{x}$ & $\mathrm{x}$ & $\mathrm{x}$ & \\
\hline Facilities and equipment developed for production in the supply chain & & & & & & $\mathrm{x}$ & $\mathrm{x}$ & \\
\hline Feedback from transport, installation, and trial operation & & & & & $\mathrm{x}$ & $\mathrm{x}$ & $\mathrm{x}$ & \\
\hline Suggested LCA activity and integration into the PDP & 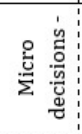 & 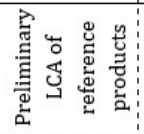 & 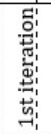 & 岕 & 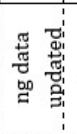 & 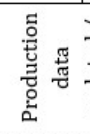 & 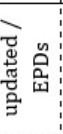 & 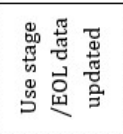 \\
\hline
\end{tabular}




\subsection{Requirement for environmental target}

The current version of the PDP does not contain mandatory deliverables for environmental targets. However, there is a strategic requirement for gate level environmental targets to be followed up throughout all the PDP steps. To operationalise that a conceptual framework was developed for integrating environmental considerations in the PDP in the form of a DfE process based on the technical report ISO/TR 14062, Integrating Environmental Aspects into Product Development. According to this DfE environmental requirements need to be set indicating life cycle stages affected and evaluating improvement potentials.

\section{LCA of a rotor blade}

An attributional LCA study was performed to quantify the overall environmental performance of a wind power blade. Its goal was to support a weak point analysis and detailed ecodesign and the functional unit and reference flow of the LCA is one rotor blade. Primary data was gathered for the foreground system, representing actual conditions at the manufacturer driving material use and consumption in the production stage based on: 1. Bill of materials (BOM): material composition of the final product; 2 . Indirect material: cut off/losses during the production process and auxiliary material required for the manufacturing processes; 3 . Other material consumed in background in the production facilities and not related directly to the final product nor to the manufacturing processes, and 4. Energy consumption, and waste production and treatment during manufacturing. All alternative suppliers providing the aforementioned materials were identified and quantities for transported mass and transport distances accurately specified.

Generic data from the life cycle inventory database ecoinvent v2.2 [15] was used for modelling of the background system, i.e. extraction of resources and production of materials and standard components, power supply, water supply, waste treatment technologies and transport technologies. Since the aim of the present study is to identify the added value brought by LCA in each step of the PDP rather than to provide specific LCA results for all impact categories and areas of protection, the results are shown only for climate change in $\mathrm{CO}_{2}$-eq for simplification and given that stakeholders in this first experience with LCA are familiar with $\mathrm{CO}_{2}$-eq but are easily overwhelmed by multiple impact categories or highly aggregated endpoint impacts.

LCA results are used to identify potential environmental improvements according to impact intensity. The main impact contributors (hot spots) are identified in two dimensions: across the life cycle of the product and within each life cycle stage to the maximum resolution level according to the available data (Figure $1 \mathrm{a}-\mathrm{c}$ ). It allows the stakeholders in each level to identify the activities over which they have an authority or influence. It also provides the scientific basis for environmental target setting. However the absolute impact scores do not give an indication of the environmental improvement potentials. To get these, the impact can be correlated with the consumption levels through an equidiagonal plot (Figure 2) so that a prioritization of environmental initiatives can be made based on the relative importance of materials. 


\section{LCA integration in PDP}

The LCA results need to be coupled with the PDP in order to evaluate the feasibility of potential initiatives and answer questions such as: where in the PDP are the decisions locked?, which is the appropriate gate for each target?, to which stakeholder group are the initiatives relevant? What kind of changes can the LCA results trigger? These questions will be answered here for the two life cycle stages that according to the LCA results count for more than $90 \%$ of the emissions viz. Direct materials and Manufacturing (Figure 1a).

a) Direct materials: include the BOM that will end up on the final product (fiberglass, epoxy, wood etc). Consumption of these materials is responsible for more than $60 \%$ of the total impacts (Figure 1a). Epoxy and fiberglass are the prevailing contributors accounting respectively for $50 \%$ and $30 \%$ of 'Direct materials (BOM)' (Figure 1-a).

Decisions related to the final product are taken and locked at the very front end of the PDP with the approval of the Product development specifications (PDS) at the end of 'Product definition' (Table 1). After that PDP point structural changes are no longer feasible and no improvement initiative can be taken. Consequently product material related environmental targets should be part of the Product Requirement Specifications (PRS) defined during scoping (Table 1).

The PRS depend on top management strategic decisions prior to PDP related to market and economic factors and are influenced by several $R \& D$ engineering groups researching the type and quantities of materials to be used in the final product. In the case under study, for a simple upgrade of the blade no environmental initiatives can be taken related to material substitution. However optimizing the design to lower the material consumption is still possible. Such target is anyway aligned with existing targets related to maximizing output and minimizing cost (more energy output with same material use). The results of the technical iterations during feasibility study can be retrofitted to a dynamic LCA model [16] which will be continuously updated, and it can then be used for hot spot identification and $\mathrm{KPI}$ appointment to each stakeholder group. In this way LCA results become embedded in the Product design specification (PDS).

Related to the direct materials the knowledge brought by LCA can be looped back in the strategic level prior to PDP as a driver for initiating new R\&D projects for substitution evaluations e.g. exploring the possibility of substituting fiberglass with alternatives. LCA can also prevent unnecessary costs of such explorations. As an example, LCA studies have shown that biobased fiberglass is not necessarily environmentally friendlier than the conventional alternative [17].

b) Manufacturing: Activities taking place during 'Design' (Table 1) are second in focus in terms of environmental relevance accounting for more than $20 \%$ of total climate change impacts (Figure 1a). The 'Manufacturing' emissions come from the consumption of indirect materials-not ending up in the final product (60\%), from total facility energy consumption (30\%) and waste (10\%) (Figure b).

Manufacturing materials are either consumed during production processes ('indirect') controlled by process engineers in the factories or they are consumables not related to production ('others') (e.g. from offices, packaging from suppliers etc) which together with the overall energy consumption and 
waste production are monitored by the facility managers. Zooming further in on the indirect materials consumed during manufacturing they can be further distinguished in a) cutoffs and losses (e.g. fiberglass and epoxy losses) identification of which gives incentives to the production engineers for process optimization and efficient material use and b) auxiliary materials that are part of the tooling and equipment in various steps of the production process (such as plastic vacuum bags used during manufacturing).

Teflon and epoxy are two materials which the LCA results indicated as major contributors in 'Manufacturing' (Figure c) and with high improvement potential. The feasibility for reducing them is realistic both according to PDP formal restrictions (the initiative does not require structural changes, and gives the possibility for production process optimization) and according to technical, supply chain and financial criteria. By reducing their consumption by $20 \%$ there will be a $3 \%$ improvement of the total climate change impacts. Conventional targets such as reducing electricity consumption would not only require higher effort but also lead to lower improvements e.g. $20 \%$ reduction of the total electricity consumption leads to a $1 \%$ improvement of the total system, 2 times lower than the savings driven by the LCA results.

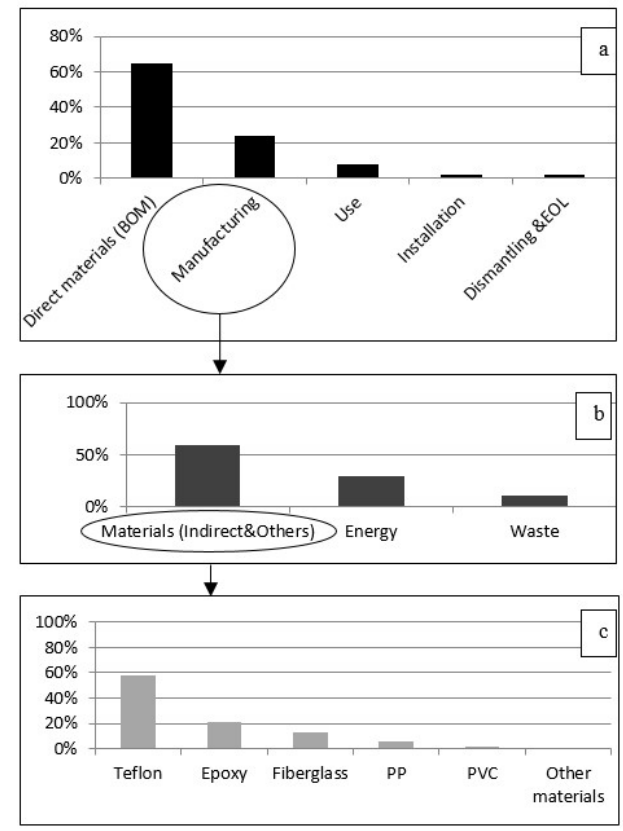

Figure 1: Climate change impact contribution $\left(\mathrm{CO}_{2}\right.$-eq) from different life cycle stages for a wind turbine blade (a), from material and energy use and waste generation in the manufacturing stage (b) and detailed material losses and auxiliaries used in manufacturing (c)

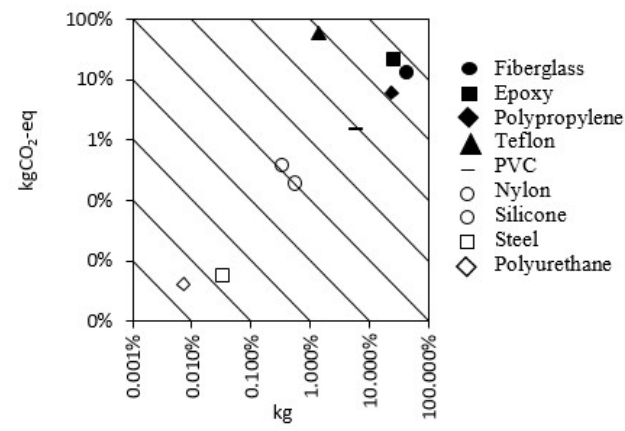

Figure 2: Relative importance of indirect materials depending on material consumption and corresponding $\mathrm{CO}_{2}$-eq emissions 


\subsection{LCA relevance to different stakeholders in PDP}

Each of the 6 identified stakeholder clusters can benefit from such an analysis and make different use of the LCA results depending on their role in the company

(1) Supply chain: A dialogue can be initiated with suppliers both in terms of data collection and target setting. Supplier rating can be done based on environmental criteria (e.g. transport distances, emission data etc.) and environmental monitoring of sourcing and planning activities related to third parties [18] can be carried out.

(2) Factories can be subjected to a dynamic monitoring and prioritized minimization of losses, auxiliary material use, waste and energy consumption during production and assembly.

(3) Design: getting the focus right when developing new products and components based on findings in the LCA.

(4) Sales: Environmental Product Declarations (EPDs) can be used for marketing and sales.

(5) Field projects: Hotspots can be identified for transport, installation and commissioning of wind turbine projects in the field and related to either own or customer's activities. Measures can be identified to mitigate existing impacts e.g. through alternative end of life (EOL) treatment scenarios [19-21].

(6) Service: Hotspots can be identified for service and maintenance activities and optimised combined with logistics. Maintenance impacts can be traded off against impacts from design and manufacture for less maintenance.

\subsection{LCA added value}

The LCA results (Table1, Figures 1a-c) give an added value to the PDP by contributing to:

(1) Identify the relative importance of different life cycle stages and what contributes most in each stage;

(2) Prioritize target setting related to the impact intensity, the improvement potential and the feasibility for each stakeholder;

(3) Prioritize actions across the PDP and the company stakeholders;

(4) Identify energy and waste reduction potentials throughout the life cycle in accordance with the internal guidance for energy savings and waste reduction;

(5) Develop an environmentally oriented supply chain management;

(6) Communicate information of environmental relevance to the costumer;

LCA can provide the basis for scientifically solid environmental improvement analysis throughout the PDP and it can contribute to all phases of an effective life cycle planning, management and control.

\subsection{Barriers for LCA integration in PDP}

To synthesize a roadmap of how LCA can be brought into use to influence the decision making throughout the PDP (Table 1), the following barriers have had to be addressed:

(1) Multiple decision contexts: To better inform decisions, the LCA goal and scope needs to be aligned with the objectives of each PDP stage. Meso/macro level decision support can be provided at the front 
end of the PDP, micro decision support can be provided throughout the PDP and environmental accounting can be done at commercialisation when all decisions and processes are locked.

(2) Change possibility: The progression from one PDP stage to the next passes through decision points where the required degree of completion is verified. Hence the possibility to make changes during the PDP is reduced as the development process progresses, and it is therefore important to identify the LCA relevance to each of the steps and effectively embed it in the process at a point where adaptation is still possible.

(3) Dynamic process: There is a need for a dynamic process where LCA results inform each design iteration the same way as all other engineering or business evaluations; a transparent platform that will at any point reflect the current state of the product's environmental performance with the level of precision that is relevant and possible.

(4) Low accuracy: The earlier in the PDP process the larger the possibility to fundamentally influence the environmental performance of the product, but also the larger the uncertainty and hence the lower the possibility of performing accurate LCAs. By embedding LCA into each PDP step, its results can be co-evaluated together with other factors under the same uncertainty condition.

(5) Commitment: Raising environmental awareness, training the relevant stakeholders and ensuring management commitment is necessary for an effective LCA integration in PDP and effective improvements.

\section{Conclusion and further research}

In the context of the growing wind power manufacturing industry this paper argued for the need to ensure product development sustainability. It introduced LCA in the PDP and proved the added value in identifying environmental improvement potentials and setting relevant environmental targets. $3 \%$ total savings were achieved due to two feasible actions driven by LCA an improvement 2 times better compared to conventional actions that would require more effort and resources. For an integration of LCA to a more strategic level, further work is needed by expanding the scope from PDP to product life cycle management process (PLM) and from a component level to the wind turbine and the wind power plant level.

Barriers related to complexity that need to be addressed include: (a) number and type of components, subject to constant engineering changes handled by elaborated intelligent management systems (b) global framework of manufacturing facilities, supply chains and life cycle stages operating simultaneously (c) long product life time and long product development time which demands information updates and dynamic integration of knowledge of past performance (d) multiple or even conflicting interests and different levels of ownership and dependency.

\section{References}

[1] IRENA, 2014, Remap., 2030: A Renewable Energy Roadmap, IRENA, Abu Dhabi, www.irena.org/remap

[2] Martínez E., Jiménez E., Blanco J., Sanz F., 2010, LCA sensitivity analysis of a multi-megawatt wind turbine, Appl. Energy,

87/ 7: $2293-2303$

[3] D'Souza N., Bgegbaje_das E., Shonfield P., 2011, Life Cycle Assessment

Of Electricity Production from a Vestas V112 Turbine Wind Plant, PE

North West Europe ApS 
[4] Hauschild M., Jeswiet J., Alting L., 2005, From Life Cycle Assessment to Sustainable Production: Status and Perspectives, CIRP Ann. - Manuf. Technol., 54/2:1-21

[5] Hauschild, M., Wenzel, H., Alting, L., 1999, Life cycle design - a route to the sustainable industrial culture? Annals of the CIRP 48/1:393-396

[6] Tan, A.R., Matzen, D., McAloone, T.-C., Evans, S., 2010, Strategies for designing and developing services for manufacturing firms, CIRP Journal of Manufacturing Science and Technology, 3/2:90-97

[7] Sundin, E., Rönnbäck, A.-Ö., Sakao T., 2010, From component to system solution supplier: Strategic warranty management as a key to efficient integrated product/service engineering, CIRP Journal of Manufacturing Science and Technology, 2/3: 183-191

[8] M. Grunow, M., Gobbi, C., 2009, Designing the Reverse Network for WEEE in Denmark, CIRP Annals - Manufacturing Technology, 58/1:391-394

[9] Hara, T., Arai, T., Shimomura, Y., Sakao T., 2009, Service CAD system to integrate product and human activity for total value, CIRP Journal of Manufacturing Science and Technology, 1/4: 262-271

[10] Kiritsis D., Bufardi A., Xirouchakis P., 2003, Research issues on product lifecycle management and information tracking using smart embedded systems," Adv. Eng. Informatics, 17/no. 3-4:189-202

[11] Maropoulos P. G., Ceglarek D., 2010, Design verification and validation in product lifecycle, CIRP Ann. - Manuf. Technol., 59/2: 740-759

[12] Peças P., Ribeiro I., Henriques E., 2014, Life Cycle Engineering for Materials and Technology Selection: Two Models, One Approach," Procedia CIRP, 15: 543-548

[13] Jayal, A.-D., Badurdeen, F., Dillon Jr., O.-W., Jawahir, I.-S., 2010, Sustainable Manufacturing: Modeling and Optimization Challenges at the Product, Process and System Levels, CIRP Journal of Manufacturing Science and Technology, 2/3:144-152

[14] Ulrich, K. and Eppinger, S., 2008, Product Design and Development, 4th ed, McGraw-Hill International, NY, USA.

[15] Ecoinvent Centre, 2007, Ecoinvent Data, Swiss Centre for Life Cycle Inventories, Dübendorf. www.ecoinvent.ch

[16] Brondi, C., Carpanzano, E., 2011, A modular framework for the LCA-based simulation of production systems, CIRP Journal of Manufacturing Science and Technology, 4/3: 305-312

[17] Birkved M, Corona A, Markussen C.-M, Madsen B., 2013, Selection of environmental sustainable fiber materials for wind turbine blades - a contra intuitive process?. Risoe International Symposium on Materials Science. Proceedings.

34:193-202.

[18] Marsillac E., Roh, J.-J., 2014, Connecting product design, process and supply chain decisions to strengthen global supply chain capabilities, International Journal of Production Economics, 147/B:317-329

[19] Duflou J.-R., Seliger, G., Kara, S., Umeda, Y., Ometto, A., Willems, B., 2008, Efficiency and Feasibility of Product Disassembly: A Case-based Study, CIRP Annals - Manufacturing Technology, 57/2:583-600

[20] Cherrington, R., Goodship, V., Meredith, J., Wood, B.-M., Coles, S.-R, Vuillaume, A., Feito-Boirac, A., Spee, F., Kirwan K., 2012, Producer responsibility: Defining the incentive for recycling composite wind turbine blades in Europe, Energy Policy, 47:13-21

[21] K. Ortegon, 2013, Preparing for end of service life of wind turbines., J. Clean. Prod., 39 